\title{
ALGUNAS REFLEXIONES EN TORNO A LAS PORTADAS DE LA GATEDRAL DE MÉXICO
}

\section{MarTha Fernández}

De todos es conocido el hecho de que debido al largo tiempo que se llevó la construcción de la catedral metropolitana, el monumento luce la mezcla de los estilos artísticos que se desarrollaron en México desde el siglo Xvi hasta el siglo xIx. Esta característica constituye una muestra de la habilidad con la que los artistas lograron incorporar al edificio cada una de las épocas artísticas sin hacerlo perder armonía, pero es también un reto para el historiador del arte que desee deslindar las etapas constructivas y los méritos de cada constructor.

En un estudio que llevo a cabo sobre la vida y obra del arquitecto Cristóbal de Medina Vargas, se me presentó la necesidad de afrontar el reto. Comencé entonces una investigación que tenía como principal tinalidad la de delimitar lo mejor posible la obra que tal artífice realizara en el monumento. Así, al revisar la bibliografía existente, encontré que una noticia publicada por Diego Angulo en su libro Planos de monumentos arquitectónicas de América y Filipinas existentes en el Archivo General de Indias ${ }^{1}$ y otra por Efraín Castro en su artículo "Juan Montero, ensamblador y arquitecto novohispano del siglo Xvr", ${ }^{2}$ resultaban de vital importancia para lograr el objetivo que me había propuesto.

No obstante, al reunir la información me di cuenta que sugería planteamientos novedosos respecto a algunas de las portadas catedralicias y respecto también a sus arquitectos.

Por la importancia de la catedral y de los datos que proporcionan los autores citados, creí conveniente exponer en un artículo dichos planteamientos, los problemas que éstos presentan y las hipótesis que propongo como posibles explicaciones al respecto. Es, en consecuencia, un artículo que más que soluciones, enuncia interrogantes y reflexiones en voz alta, que sólo se podrán convertỉr en afirmaciones con la aparición de nuevos y más precisos textos documentales.

1 Diego Angulo Iñiguez, Planos de monumentos arquitectónicos de América y Filipinas existentes en el Archivo General de Indias, 3 t., Sevillia, Laboratorio de Arte, Universidad de Sevilla, 1933, t. r, pp. 171-172.

2 Efrain Castro Morales, "Juan Montero, ensamblador y arquitecto novohispano del siglo xvin", en Boletin Monumentos Históricos, Instituto Nacional de Antropologia e Historia, 6 (México, 1981), pp. 5-26. 


\section{Las noticias}

Las noticias que nos han servido de punto de partida para realizar la investigación son las siguientes:

En el artículo citado "Juan Montero, ensamblador y arquitecto novohispano del siglo xvir", Efraín Castro publicó parcialmente una Información Testimonial de Juan Montero de Espinosa. Como explica el autor, el documento fue preparado con el objeto de que al artista se le otorgara el nombramiento de maestro mayor de la catedral de México, de manera que la médula del manuscrito es precisamente la relación de los trabajos que Montero llevó a cabo en el templo. Contiene las declaraciones de cinco testigos y fue redactado del 7 al 11 de septiembre de 1684 .

Según la versión paleográfica publicada por Castro, en estas declaraciones los testigos coinciden en que Juan Montero "... intervino en la prosecución de la puerta principal de enmedio desde la segunda cornisa hasta el tablero del escudo de las armas reales..." y que levantó las portadas procesionales " ". . cogiéndolas o formándolas desde su principio y se van continuando ." 3

Por su parte, desde 1933 Diego Angulo publicó en sus Planos de monumentos arquitectónicos de América y Filipinas existentes en el Archizo General de Indias, que el 29 de mayo de 1699 los arquitectos Cristóbal de Medina, Diego Martín de Herrera, Diego Rodríguez y Pedro de Arrieta manifestaron que faltaba ". . el último cuerpo a cada una..." de las portadas procesionales, el cual estaría constituido por "... banco, columnas, y traspilares con sus bazas y capiteles, y en el intervalo de ellas la ventana o clarabolla con su recuadro, su alquitrave, frisso, cornija, y remate..." Mientras que la portada del Perdón aún no contaba con ". . .los capiteles del último cuerpo, alquitrave, frisso, cornija, frontis y remates". 4

Reuniendo todos los datos, se presentan tres problemas principales: el número de cuerpos que deberían haber tenido las portadas catedralicias, su cronología y sus autores.

\section{Los cuerpos de las portadas}

El enunciado de este problema sería: en 1699 aún faltaba concluir en lo esencial en "último" cuerpo de la portada del Perdón y en 1684

3 Ibid., pp. 24-26.

4 Diego Angulo Iñiguez, op, cit., $t$. 1, pp. 171-172. 
Juan Montero había proseguido esta misma portada “. . . desde la segunda cornisa.... " Del mismo modo, en 1699 se planeaba construir el "último" cuexpo de las portadas procesionales, que entre otras cosas tendría “. ventana o clarabolla..." y cuyas columnas no parece que fueran a contar con alguna característica especial.

Comencemos por las portadas procesionales. El primer cuerpo conserva un estilo de raigambre completamente manierista, mientras que el segundo es salomónico, esto es, barroco; tiene columnas pareadas y un relieve al centro en lugar de la ventana.

La primera hipótesis que se puede plantear es que después de 1699 se sustituyera la ventana del proyecto transcrito, por el relieve y se levantaran columnas salomónicas para darle a las portadas un carácter más compatible con la moda artística del momento (barroca) y con las portadas del crucero que se habían concluido diez años antes. Pero esta hipótesis tendría dos fallas: por un lado, serían columnas salomónicas muy tardías, y por otro, y más importante aún, los relieves.

Se ignora el nombre de los autores de tales relieves y su fecha de colocación, sin embargo se han atribuido con buen crédito a los hermanos Nicolás y Miguel Ximénez, quienes en 1687 firmaron y fecharon las esculturas exentas de San Pedro y San Pablo que aún se conservan en la portada del Perdón. ${ }^{5}$ La atribución está basada en el hecho de que tanto los relieves como las esculturas parecen obras de un mismo taller, amén de que su estilo es el mismo: barroco con la persistencia de formas manieristas.

Es de suponerse entonces que tanto las relieves como las esculturas hayan sido más o menos contemporáneas, o sea de los años ochenta $o$ principios de los noventa del siglo xvII.

De esta manera llegamos a la conclusión de que para 1699 tuvo que haber estado construido el segundo cuerpo de las portadas procesionales, lo que significa que el "último" cuerpo al que hace alusión Cristóbal de Medina es otro cuerpo distinto. $Y$ es así como podemos llegar a la segunda hipótesis: lo que pretendían levantar los maestros de la catedral en 1699 era un tercer cuerpo en las portadas procesionales compuesto por banco, columnas - seguramente de ascendencia clásica dado que no se menciona que fueran a ser "tortuosas" o salomónicas-, ventana

5 Manuel Toussaint, La catedral de México y el Sagrario Metropolitano. Su historia, su tesoro, su arte, prólogo y notas a la segunda edición por Gonzalo Obregón, $2^{a}$ ed., México, Éditorial Portúa, 1973, pp 79-81. 
o claraboya para permitir la iluminación directa a las naves procesionales desde la entrada, y remate.

Además de los argumentos expuestos, esta hipótesis se puede sustentar en dos factores más: por un lado, en el hecho de que las portadas del crucero tienen tres cuerpos, y por otro, en el proyecto original de la portada del Perdón, portada de la cual nos ocuparemos en seguida.

La hipótesis viable respecto a la portada del Perdón es la siguiente: en 1684 Juan Montero comenzó a construir el tercer cuerpo, mismo que todavía no se había concluido en 1699. Para sustentar esta idea podemos exponer los siguientes argumentos:

Primero: las declaraciones de la Información Testimonial de Juan Montero (1684) en las que se afirma que el arquitecto prosiguió la portada "... desde la segunda cornisa...", lo que interpretamos como: a partir de la cornisa del segundo cuerpo.

Segundo: el relieve que luce el segundo cuerpo. Igual que los relieves de las portadas procesionales este relieve se ha atribuido a los hermanos Ximénez, por lo tanto debe suponerse contemporáneo a ellos, o sea de los ochenta o principios de los noventa del seiscientos.

Tercero: el proyecto original de la portada. Todos sabemos que de acuerdo al informe presentado por Luis Gómez de Trasmonte y Rodrigo Díaz de Aguilera en 1672 la portada estaba planeada en tres cuerpos: dórico, jónico y compuesto, ${ }^{6}$ de tal suerte que se puede pensar que Juan Montero pretendiera complementar la portada conforme a este programa.

Cuarto: este último fundamento depende de la confirmación de la hipótesis de que en 1699 se pretendía levantar un tercer cuerpo a las portadas procesionales. Esto es, que si en 1699 la portada del Perdón no hubiera tenido parcialmente construido el tercer cuerpo, habría carecido de sentido que las procesionales lo fueran a tener, a la vez que si las procesionales no hubieran contemplado ese año un tercer cuerpo, parecería imposible que la del Pardón lo tuviera.

Es fácil imaginar ese tercer cuerpo gracias a la declaración que emitió el arquitecto José Durán en la Información Testimonial de Juan Montero. Según él "...el susodicho siguió la forma antigua de la por-

${ }^{6}$ Efraín Castro Morales, op.cit., pp. 21-23 "Martha Fernández: Arquitectura y gobierno virreinal. Los maestros mayor es de la ciudad de México. Siglo XVII, presentación de Jorge Alberto Manrique, México, Instituto de Investigaciones Estéticas, Universidad Nacional Autónoma de México, en prensa, documento número xx. Apud: AGI (Audiencia de México: 46, ramo d, doc. 41-A). 
tada de enmedio..." 7 O sea que Montero respetó el estilo de los cuerpos construidos: el manierista, y es posible que también pretendiera que fuera compuesto, pues se sabelque desde el 18 de mayo de 1678 Montero fue nombrado aparejador mayor de la catedral, ${ }^{8}$ por lo tanto podemos suponer que conocería el proyecto de Gómez de Trasmonte y Díaz de Aguilera.

Con todo esto llegamos a una conclusión 'importante: todos los proyectos de las portadas catedralicias del imafronte contemplaban tres cuerpos, lo que parece lógico de acuerdo al ancho que de torre a torre tiene el edificio: tres cuerpos en cada portada lo habría quizá dotado de mejor proporción y'de mayor monumentalidad.

Ahora bien, ¿qué sucedió a esos terceros cuerpos proyectados? De todo lo dicho, parece que en 1699 estaba semilevantado el de la portada del Perdón y se pensaba construir los de las portadas procesionales. De acuerdo con los informes de las obras que se llevaron a cabo en el templo durante el siglo xviII, conocidos hasta ahora, parece que los de las procesionales ya no se edificaron, mientras que el tercer cuerpo de la portada del Perdón debió convertirse en el remate que Manuel Tolsá derribó para colocar el que vemos actualmente.

\section{La cronologia}

La primera portada que se comenzó a construir después de las del norte fue la del Perdón. El primer cuerpo fue obra de los maestros Luis Gómez de Trasmonte y Rodrigo Díaz de Aguilera; se concluyó en 1672, año en que se empezó la fábrica del segundo cuerpo. ${ }^{9}$ En 1684 los testigos que presentó Juan Montero en su Información Testimonial afirman, como hemos visto, que este arquitecto había proseguido la portada “... desde la segunda cornisa...", lo cual, aunado a los argumentos expuestos en el apartado anterior, implica que el segundo cuerpo ya estaba terminado para entonces.

De la propia Información Testimonial se desprende que para 1684 se había construido parte de las portadas procesionales, las cuales, a decir de los testigos, "... se van continuando..."

En 1688 se concluyó la portada oriente del crucero y en 1689 la

7 Efrain Castro Morales, op cit., p. 25.

8 Martha Fernández, op. cit.; Apud: AGI (Audiencia de México: 2708).

9 Efraín Castro Morales, op cit., pp. 21-23. Martha Fernández, op. cit., documento número xx; Apud: AGI (Audiencia de México: 46, ramo 4, doc 41-A). 
poniente, ambas bajo la dirección del arquitecto Cristóbal de Medina Vargas.

En 1689, los quince arquitectos de la catedral, entre los que se encontraban Juan Montero y Cristóbal de Medina, se reunieron para reconocer la obra y revisar lo que faltaba por realizarse. Entre los trabajos que se propusieron llevar a cabo se encontraba la conclusión de las portadas procesionales, ${ }^{10}$ objetivo que nunca alcanzaron porque, como hemos visto, en 1699 el propio Medina y un grupo de maestros de la catedral afirmaron que todavía se necesitaba construir el último 'cuerpo de dichas portadas, en tanto que a la del Perdón se le tenían que levantar los capiteles del último cuerpo, arquitrabe, friso, cornisa, frontis y remates. Según explicamos en el apartado antexior, los últimos. cuetpos a los que se hace referencia en esta declaración, deben corresponder a los terceros cuerpos de las portadas.

Así tenemos que de acuerdo a los datos conocidos hasta ahora, de lo único que podemos estar más o menos seguros es de lo siguiente: en 1672 se concluyó el primer cuerpo de la portada del Perdón y se inició el segundo; entre 1672 y 1684 se terminó ese segundo cuerpo. En 1684 se había iniciado su tercer cuerpo y se habían comenzado a construir las portadas procesionales. En 1688 y 1689 se finalizaron las portadas del crucero. En 1699 seguramente se habían levantado los dos primeros cuerpos de las portadas procesionales y se proyectó construir los terceros, y dar fin al tercer cuerpo de la portada del Perdón. Lo que nos corresponde realizar ahora es tratar de precisar un poco más las fechas de construcción del segundo cuerpo de la portada del Perdón y de los dos primeros cuerpos de las procesionales.

\section{La portada del Perdón}

Hemos dicho que en 1672 se inició la construcción del segundo cuerpo de la portada del Perdón y que ya estaba terminado en 1684. Estos doce años de distancia pueden dividirse en tres periodos conforme a los arquitectos responsables de la obra: de 1672 a 1678, de 1678 a 1682 y de 1682 a 1684.

De 1672 a 1678 Luis Gómez de Trasmonte era el maestro mayor y Rodrigo Díaz de Aguilera el aparejador mayor. El 30 de abril de 1678

10 Martha Fernándex, op. cit; Apud: AGI (Audiencia de México: 471, fol. 32 vto. 34 vto.). 
murió Rodrigo Díaz de Aguilera ${ }^{11}$ y días más tarde fue nombrado en su lugar Juan Montero de Espinosa.

El 3 de junio de 1679, Cristóbal de Medina fue nombrado maestro mayor de la catedral de México en las ausencias y enfermedades de Luis Gómez de Trasmonte, recibiendo la confirmación real en cédula de 13 de mayo de $1680 .{ }^{12}$

En 1682 se declaró que Luis Gómez de Trasmonte se encontraba totalmente impedido ${ }^{13}$ y a partir de entonces desaparecen las noticias respecto a su trabajo. En vista de esta circunstancia, lo lógico era pensar que Cristóbal de Medina tomara las riendas de la catedral en su calidad de maestro mayor interino, sin embargo no fue así, pues en su Probanza de méritos y servicios se dice claramente que el arquitecto hizo valer su interinato hasta el 11 de septiembre de $1684,{ }^{14}$ o sea sólo unos días antes de la muerte de Luis Gómez de Trasmonte ocurrida el 28 de septiembre. ${ }^{15}$ Esto nos indica que de 1682 at 1684 el responsable real de las obras fue Juan Montero.

Ahora bien, no existe dato en ninguno de los tres periodos que nos dé la certeza de la construcción del segundo cuerpo de la portada del Perdón; no obstante, la Información Testimonial de Juan Montero nos proporciona una luz al respecto.

Como afirma Efraín Castro, este documento fue realizado para un objetivo concreto: que se le otorgara a Juan Montero la maestría mayor de la catedral de México. ${ }^{16}$ Según vimos, Cristóbal de Medina ya había obtenido el interinato de su nombramiento desde 1679, de tal forma

11 Ibid; Apud: ASM (Iibro de difuntos españoles, años 1671-1680, fol 251 vto.).

12 Ibid,; Apud: AGI (Audiencia de México: 1100, lib, 36, fol. 398 vto 400 vto.) AGI (Audiencia de México: 560) y AGI (Audiencia de México: 163, ramo 2, doc. 28). El último documento aparecerá publicado integro en el libro que preparo para el Instituto de Investigaciones Estéticas de la Universidad Nacional Autónoma de México, sobre la vida y obra de Cristóbal de Medina Vargas Machua. Martha Fernández, "Cristóbal de Medina Vargas y el Acueducto de Santa Fe", en Estudios sobre Arte Novohispano. Homenaje a Elisa Vargas Lugo, Instituto de Investigaciones Estéticas, Universidad Nacional Autónoma de México, 1983, Apud: documentos citados.

13 Martha Fernández, Arquitectura y gobierno virreinal; Apud: AGI (Audiencia de México: 163, ramo 2, doc. 28).

14 AGI (Audiencia de México: 163, ramo 2, doc. 28).

15 Martha Fernández, Arquitectura y gobierno virreinal, documento número vi; Apud: ASM (Libro de difuntos españoles, años 1681-1686, fol 213 vto.) Efraín Cástro Morales, "Los maestros mayores de la catedral de México", en Artes de México, año XXI, 182-183 (México, 1976), p. 142.

16 Efraín Castro Morales, "Juan Montero, ensamblador y arquitecto novohispano del siglo Xvir", p. 23. 
que en 1684 contaba Montero con el obstáculo de un nombramiento otorgado y confirmado a otro arquitecto. Así, el documento tenía que presentar la obra de Juan Montero en catedral como algo suficientemente importante como para que, si no era posible ya revocar el interinato, al menos no se le diera la titularidad a Medina.

Can tal fin, vemos que Montero exagera un tanto su labor atestiguada en la Información Testimonial, de modo que, por ejemplo, cuando los declarantes dicen que Montero había proseguido la portada del Perdón ". desde la segunda cornisa hasta el tablero del escudo de las armas reales ..", parece dar a entender que ya estaba terminado todo ese trabajo, cosa que, como hemos visto, es falsa, puesto que en 1699 no estaban hechos ni siquiera los capiteles. Pero lo importante en este caso no es ese exceso de ponderación, sino que pese a ello, Montero no menciona nunca que haya hecho nada en el segundo cuerpo de la portada, lo que significa que en 1678, año en que Montero fue nombrado aparejador mayor de la catedral, dębió estar ya terminado ese segundo cuerpo. Esto cerca su fecha de construcción al primer periodo que hemos señalado, o sea, de 1672 a 1678, bajo la dirección de Luis Gómez de Trasmonte y Rodrigo Díaz de Aguilera.

Ahora bien, según Efraín Castro, este segundo cuerpo fue modificado 17 En efecto, parece que en 1678 no estaba como lo vemos actualmente; en época que trataremos de precisar ahora, se agregaron los tableros del banco y de los intercolumnios y las estrías zigzagueantes horizontales del primer tercio de las columnas.

Como hemos dicho, es muy probable que de 1678 a 1684 Montero no hubiera hecho nada en el segundo cuerpo de la portada, por lo tanto hemos de suponer que los cambios debieron hacerse después de 1684 cuando el responsable de las obras era ya Cristóbal de Medina. Conforme a los datos reunidos, el trabajo de este arquitecto en catedral puede dividirse en dos periodos: de 1684 a 1689 y de 1689 a 1699.

De 1684 a 1689 lo único que tenemos documentado es la construcción de las portadas del crucero (concluidas en 1688 y 1689). En 1689 pretendía dirigir la conclusión de las portadas procesionales y la primera torre, propósitos que no alcanzó. ${ }^{18}$

En 1693, acompañado por Juan Montero, Diego Rodríguez y Juan

17 Ibid., p 26.

18 Martha Fernández, Arquitectura y gobierno virreinal. Apud: AGI (Audiencia de México: 471 , fol, 32 vto.-34 vto.). 


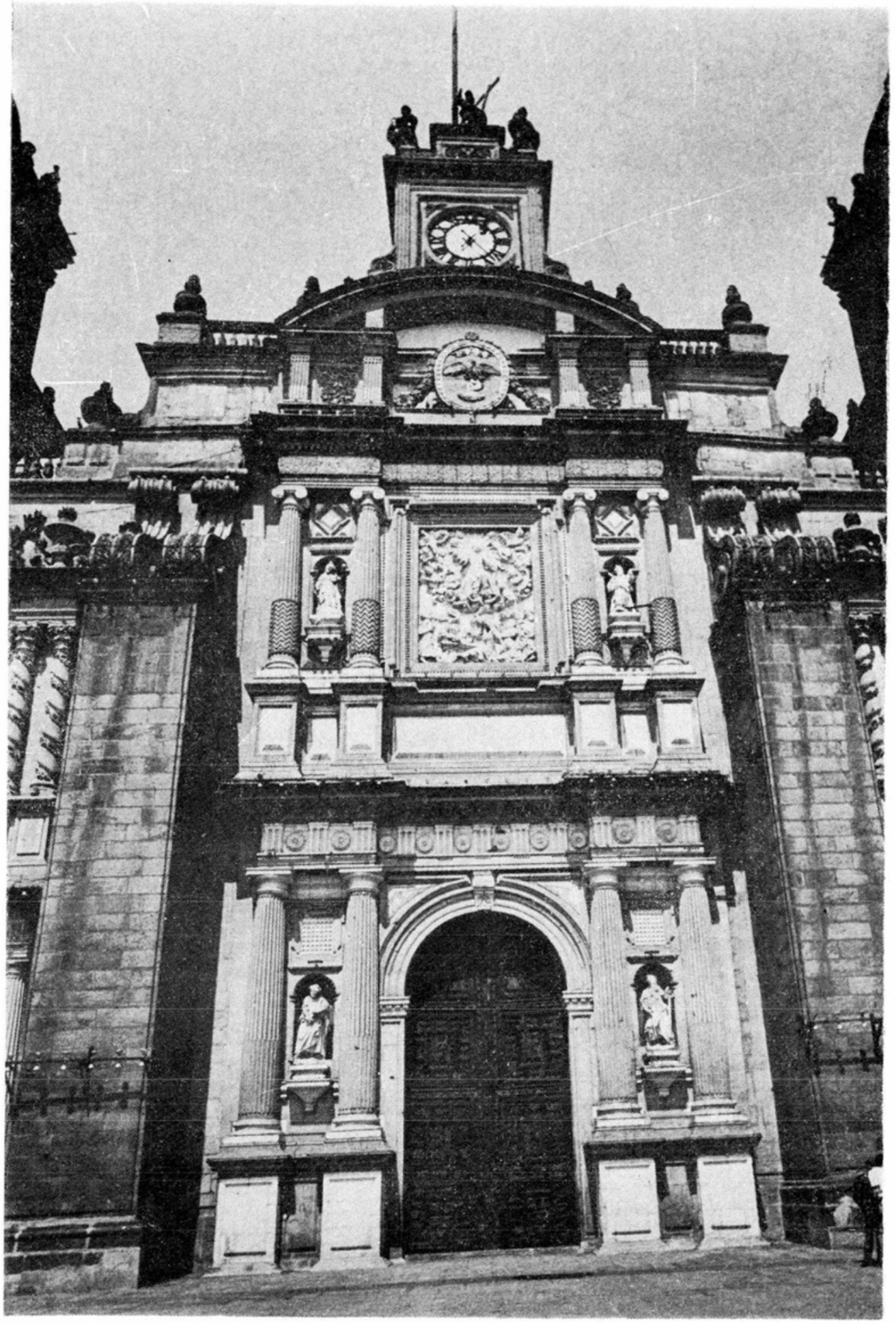

Figura 1. Catedral de México. Portada del Perdón. Foto EVL, IIE. 


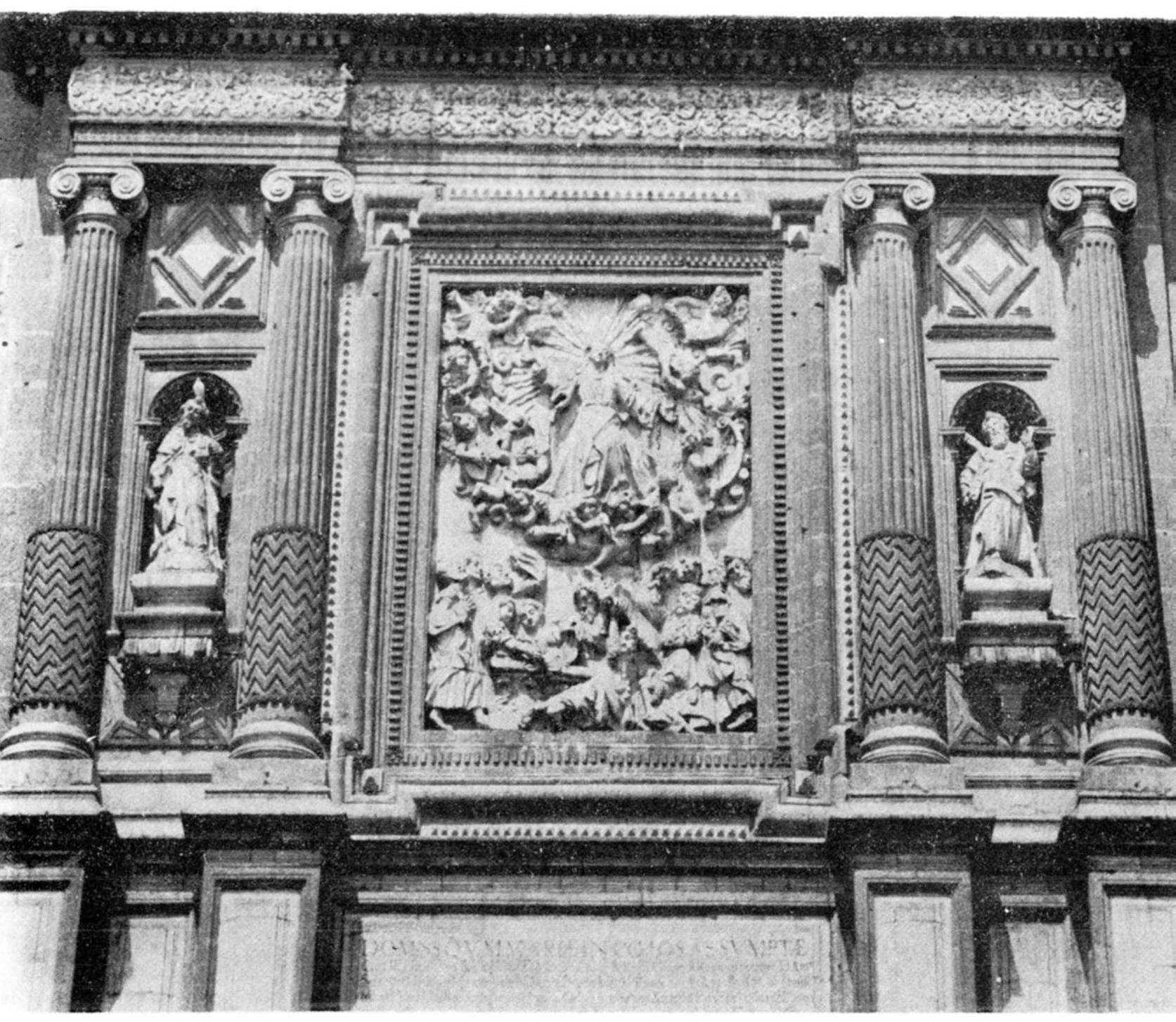

Figura 2. Catedral de México. Portada del Perdón. Segundo cuerpo. Foto MERG, IIE. 
DOI: http://dx.doi.org/10.22201/iie.18703062e.1983.53.1218

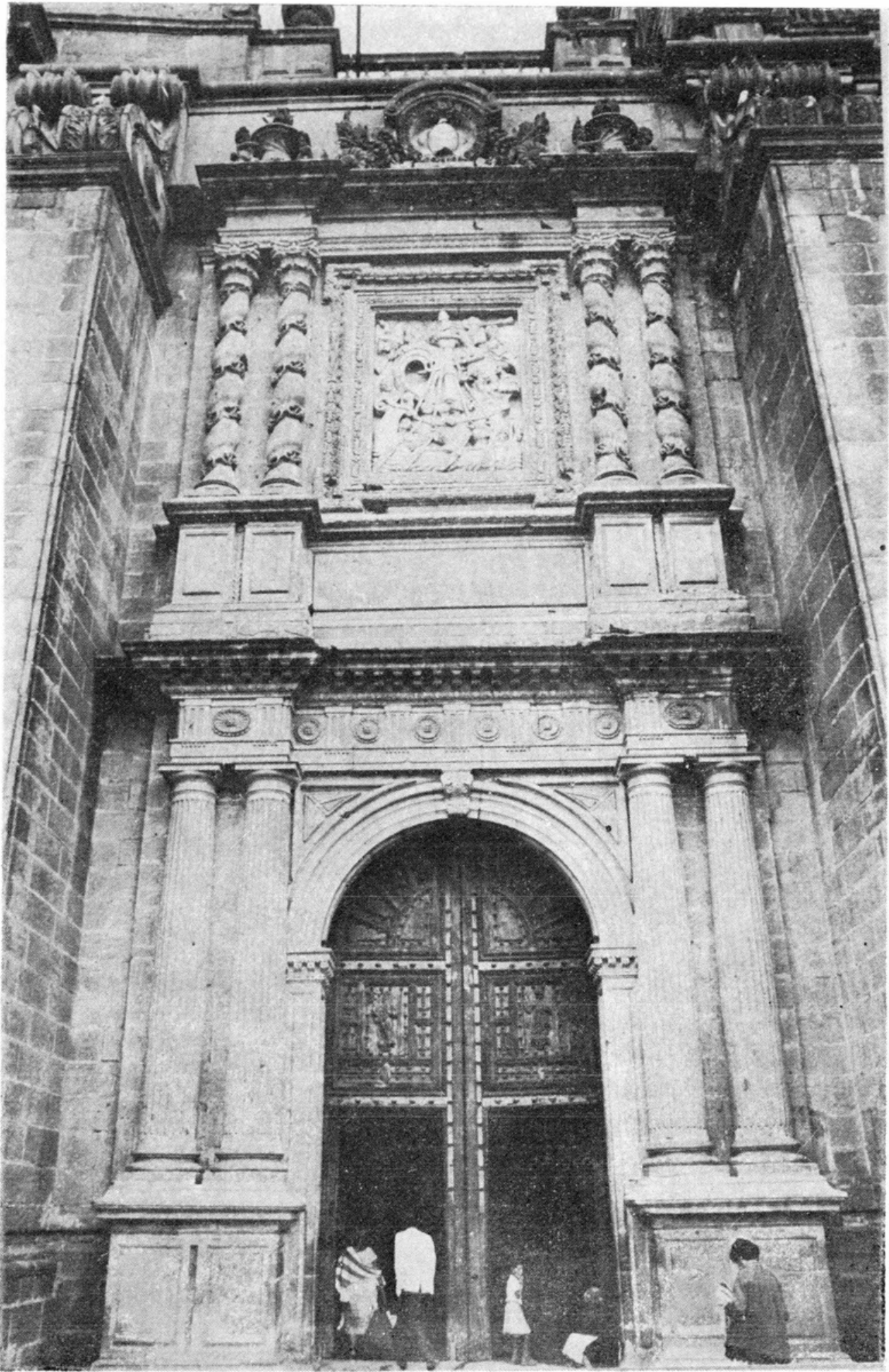

Figura 3. Catedral de México. Portada procesional derecha. Foto RHF, IIE. 


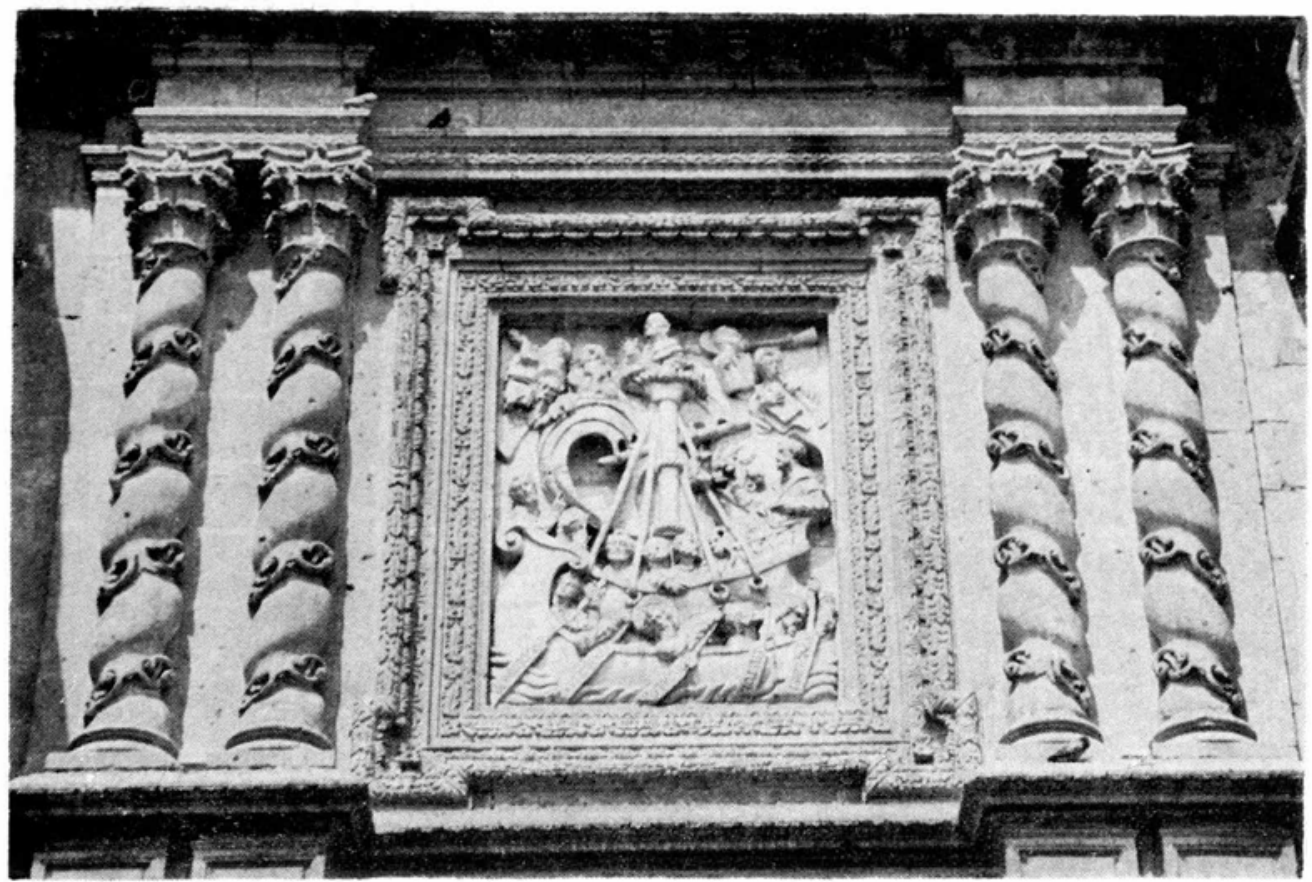

Figura 4. Catedral de México. Portada procesional derecha. Segundo cuerpo. Foto MERG, IIE.

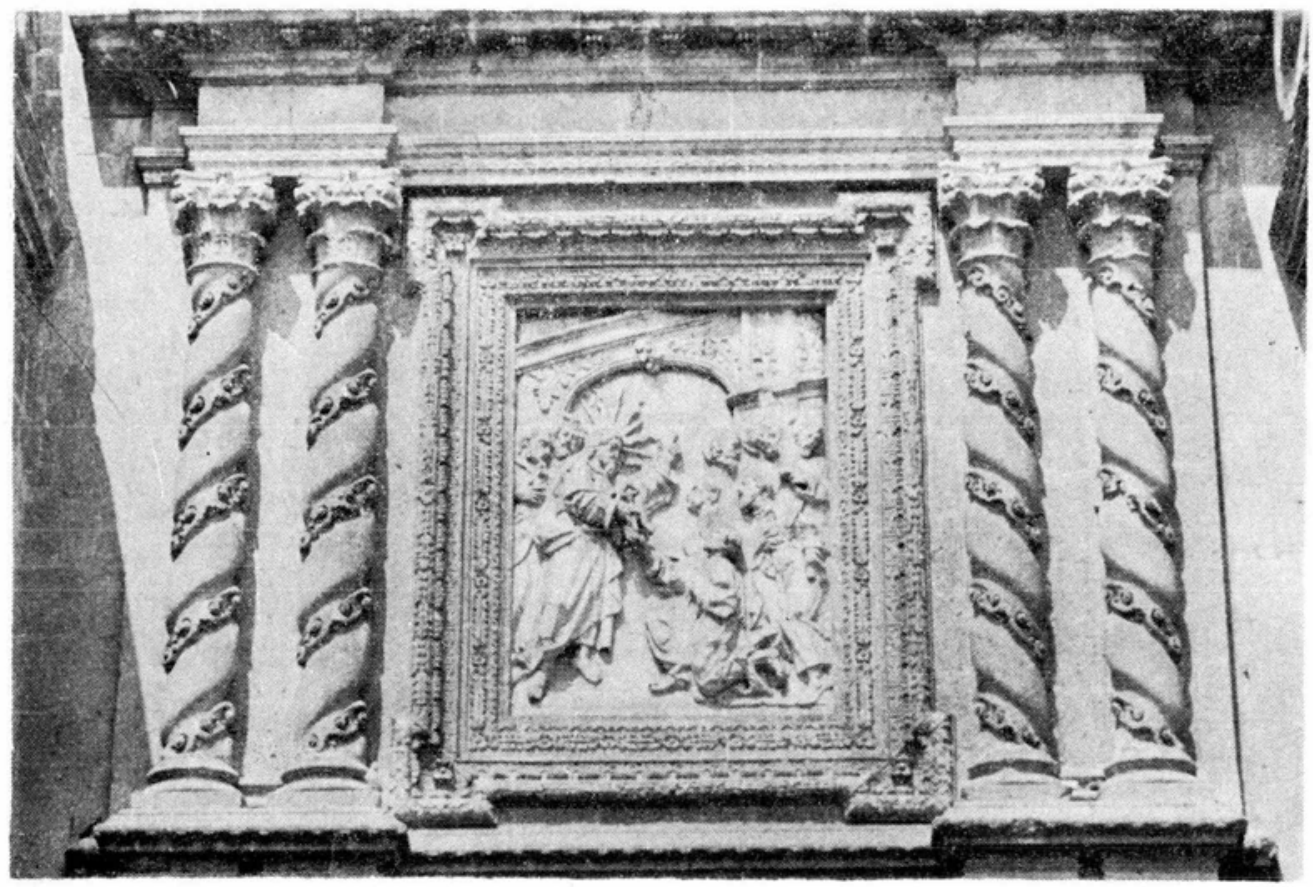

Figura 5. Catedral de México. Portada procesional izquierda. Segundo cuerpo. Foto MERG, IIE. 


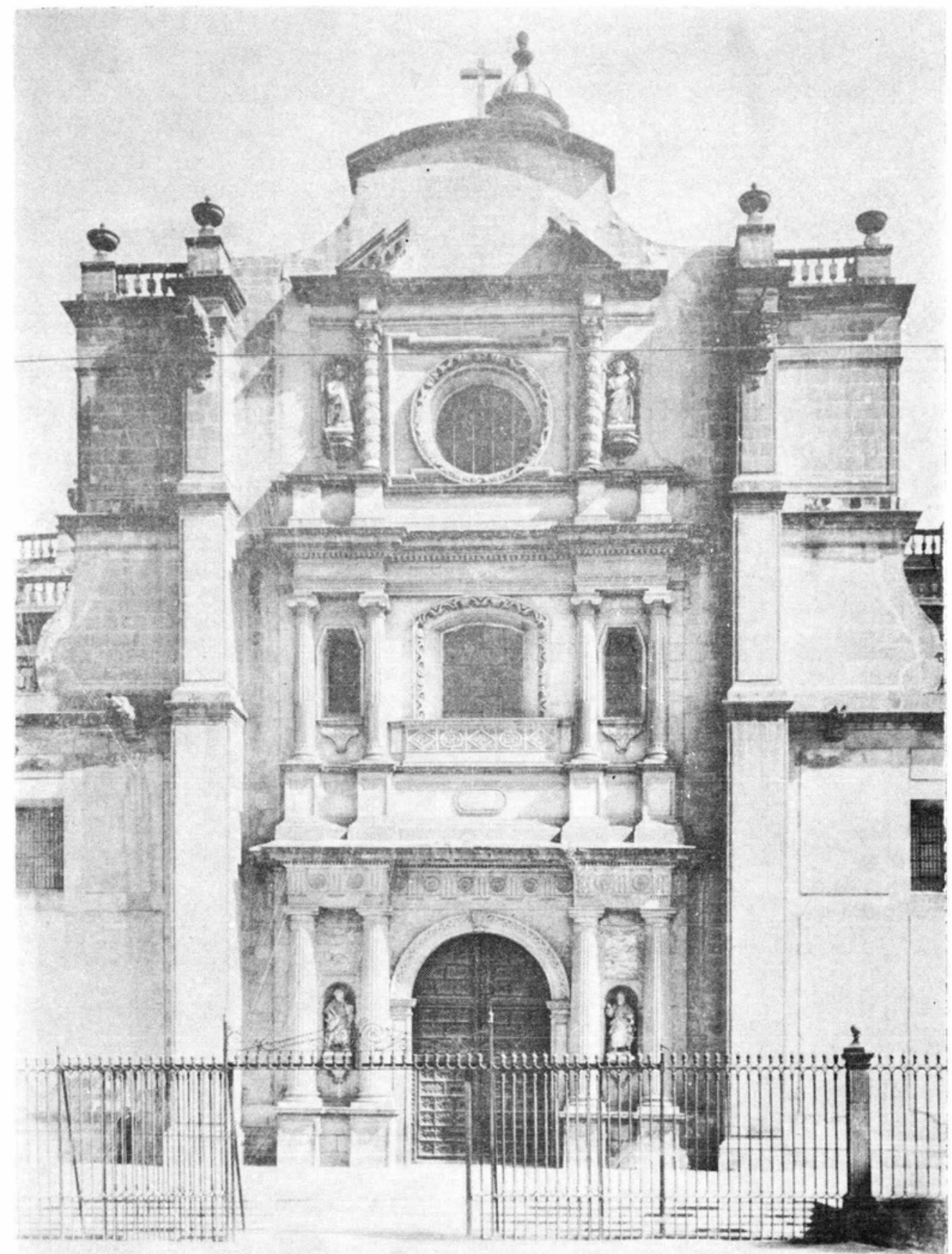

Figura 6. Catedral de México. Portada poniente del crucero. Foto FM. IIE. 
DOI: http://dx.doi.org/10.22201/iie.18703062e.1983.53.1218

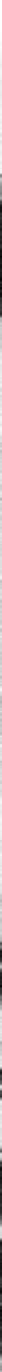

Figura 7. Catedral de México. Portada poniente del crucero. Tercer cuerpo. Foto RMR, IIE. 


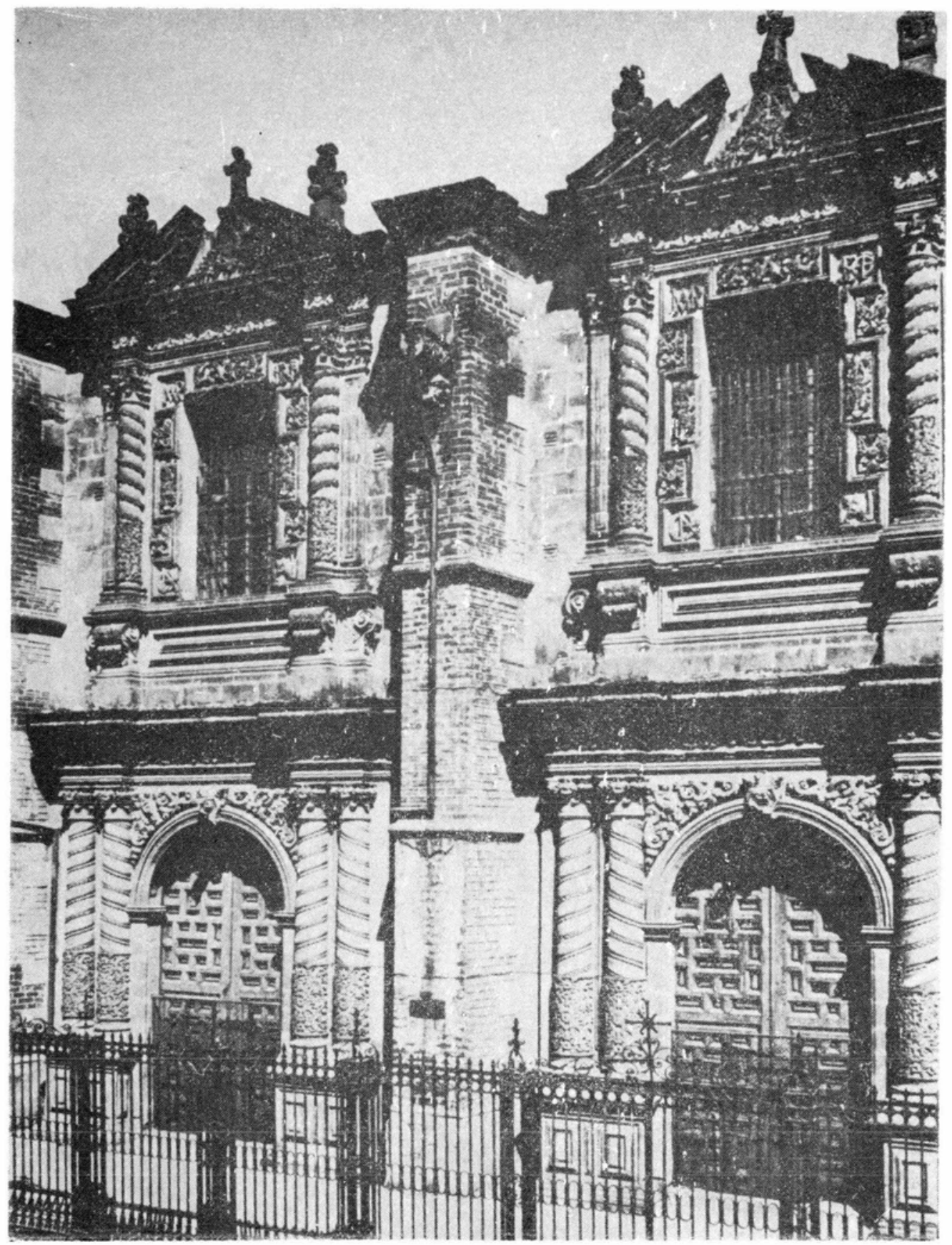

Figura 8. Templo de Santa Teresa la Antigua. Portadas. Foto tomada del libro de Manuel Toussaint: Arte colonial en México. 
DOI: http://dx.doi.org/10.22201/iie.18703062e.1983.53.1218

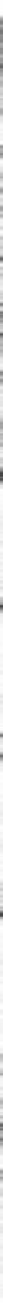

Figura 9. Templo de San Agustín. Segundo cuerpo. Foto JLRP, IIE. 
de Cepeda “.. exhibió y manifestó las plantas de perspectiva del adorno, arcos y capillas, bóvedas y ventanaje de la catedral de México de la parte de adentro y asimismo, la planta y dibujo de la fábrica que se ha de hacer para el Sagrario..."

En 1699, además de ratificar la declaración de 1693, ${ }^{19}$ explicó, como se ha dicho, que faltaba concluir el último cuerpo de la portada del Perdón y levantar el último cuerpo de las portadas procesionales. Cristóbal de Medina murió el 12 de agosto de 1699,20 de tal manera que nada de esto se pudo llevar a cabo bajo su maestría mayor.

A juzgar por estos datos documentales, da la impresión de que a partir de 1689 no se pensaba hacer nada en el segundo cuerpo de la portada del Perdón, de ahí que hayamos de suponer que sus modificaciones debieron llevarse a cabo entre 1684 y 1689 , o sea, contemporáneas a las portadas del crucero. Idea que resulta lógica si nos damos cuenta que una portada demasiado clasicista al frente resultaría incompatible con portadas barroquizantes en el crucero.

En conclusión tenemos que todo parece indicar que el segundo cuerpo de la portada del Perdón debió levantarse entre 1672 y 1678 y sus modificaciones debieron realizarse entre 1684 y 1689.

\section{Las portadas procesionales}

En la Información Testimonial de Juan Montero se dice que él levantó estas portadas “....cogiéndolas o formándolas desde su principio y se van continuando..." Lo que implica que Montero comenzó la construcción de las portadas, pero çcuándo? Claramente asienta la información que las estaba haciendo "... actualmente en el tiempo presente de la ausencia y enfermedad del dicho maestro mayor Luis Gómez de Trasmonte.

Como todo ser humano, Luis Gómez de Trasmonte debió enfermarse y ausentarse de la obra varias veces a lo largo de su vida, pero antes de 1682 no parece que ninguna de sus enfermedades fueran largas. De acuerdo a los datos que hemos reunido, a partir de 1678 dejan de aparecer noticias sobre su participación en la catedral, pero no en relación a su actividad en otras obras como casas habitación y conventos

19 Ibid., Apud: AGI (Audiencia de México: 810, fol. 8 vto--16 vto, 18 r.-29 r., 29 vto $-30 \mathrm{r}$ )

20 Ibid.; documento número vir.; Apud: ASM (Libro de difuntos españoles, años 1698:1707, fol. 36 r:). 
de monjas; ${ }^{21}$ incluso en 1680 viajó a Veracruz para reconocer los sillares que se habrían de emplear en el recalce del castillo de San Juan de Ulúa, ${ }^{22}$ lo que viene a ser indicativo de que Gómez de Trasmonte gozaba de salud y fortaleza. Es a partir de 1682 cuando podemos decir, como se dijo entonces, que ya se encontraba totalmente impedido y por lo tanto su actividad decayó notablemente, tanto que es posible pensar que tal vez ni siquiera hubiera podido asistir con frecuencia a la catedral

Por otra parte, si bien carecemos de información sobre la participación de Gómez de Trasmonte en catedral, también es cierta la ausencia, hasta el momento, de noticias precisas relacionadas con las obras del edificio en ese periodo. Si, como suponemos, entre 1672 y 1678 se levantó el segundo cuerpo de la portada del Perdón, entre 1678 y 1682 resulta que nada o casi nada se habrá hecho en el monumento, al menos en relación a sus portadas.

Finalmente, suponiendo que Juan Montero, por las conveniencias mencionadas anteriormente, hubiera exagerado sus méritos y en realidad no hubiera dirigido la construcción de las portadas desde el principio, sino que en 1684 las estuviera solamente continuando, tendríamos que suponer que el mérito corresponde a Luis Gómez de Trasmonte, puesto que cuando menos hasta 1682 estuvo activo. Su estilo, por otra parte, es muy cercano, en ese primer cuerpo, al primero de la del Perdón.

Sin embargo, dado que la única noticia más o monos segura del inicio de la construcción de tales portadas es el informe de Montero y lo demás son especulaciones, tenemos que aceptar hasta el momento que don Juan inició la construcción de las portadas procesionales, solo, sin la dirección del maestro mayor.

Si a esto aunamos el hecho de que para 1684 las portadas se iban "continuando", o sea que ya había construido algo, podemos calcular que se iniciaron entre 1682 y 1683 .

Ahora bien, recordemos que en 1684 Cristóbal de Medina hizo valer su interinato de maestro mayor de la catedral, interinato que se convir-

21 Ibid, documento número xxv, Apud: AN (Notario José de Anaya: $1^{\circ}$ de febrero de 1679 , fol. 28 vto -32 r; 8 de febrero de 1679 , fol. $37 \mathrm{r}$. 38 vto; 26 de marzo de 1678 , fol 106 r.); AN (Notario Pedro Deza Ulloa, año de 1679, v. II, lib. II, fol. 166 vto); AGN (Bienes Nacionales: 242, doc s/n). Glorinella González Franco, Ana Eugenia Reyes y Cabañas y Angelina Olivas Vargas, "Notas para una guía de artistas y artesanos de la Nueva España I", en Boletin Monumentos Históricos, Institu to Nacional de Antropología e Historia, I (México, 1979), p. 67.

22 Martha Fernández, Arquitectura y Gobierno Virreinal. Apud: AGI (Audiencia de México: 864 , fol $32 \mathrm{r},-33 \mathrm{r}$ ). 
tió en titularidad el 3 de octubre de 1684, ${ }^{23}$ lo que conlleva el hecho de que a partir de ese instante Medina se responsabilizó de la obra.

Así las cosas, resulta que entre 1682 y 1684 Juan Montexo tuvo sólo dos años para realizar sus trabajos en catedral. En ese lapso inició, como hemos visto, el tercer cuerpo de la portada del Perdón que dejó inconcluso, y en cuanto a las procesionales, trabajando de prisa pudo quizá terminar su primer cuerpo.

Con esto tenemos las siguientes fechas: de 1682-83 a 1684 parece que se construyó el primer cuerpo de las portadas procesionales, y en 1699 se pretendía levantar el tercero. De esta manera, entre 1684 y 1699 se debió construir el segundo cuerpo.

Como se ha dicho, esos quince años bajo la maestría mayor de Cristóbal de Medina se dividen en dos periodos: de 1684 a 1689 y de 1689 a 1699. En vista de que por las declaraciones emitidas de 1689 a 1699 da la impresión de que se avanzó poco en la catedral y nada en las portadas, de que ninguno de los proyectos planeados en aquellos años se llevó a cabo, y puesto que, por otra parte, los relieves de las portadas se consideran contemporáneos a las esculturas de San Pedro y San Pablo que luce la portada del Perdón (1687), parece más lógico pensar que el segundo cuerpo de las portadas procesionales se levantara entre 1684 y 1689, es decir, al mismo tiempo que las portadas del crucero y las modificaciones del segundo cuerpo de la portada del Perdón.

\section{Los arquitectos}

Si atendemos a la cronología que hemos establecido, la paternidad de las portadas estudiadas resulta más o menos clara y el mérito lo comparten cuatro arquitectos: Luis Gómez de Trasmonte, Rodrigo Díaz de Aguilera, Juan Montero de Espinosa y Cristóbal de Medina Vargas Machuca. Su obra sería la siguiente:

Luis Gómez de Trasmonte y Rodrigo Díaz de Aguilera levantaron el primer cuerpo de la portada del Perdón y debieron construir el segun-

23 AGI (Audiencia de México: 163, ramo 2, doc. 28). Heimrich Berlin, "Artifices de la Catedral de México (Investigación en el Archivo General de la Nación)" en Anales del Instituto de Investigaciones Estéticas, Universidad Nacional Autónoma de México, III, 11 (México, 1944), p. 32; Apud AGN (Duplicado de Reales Cédulas: 28, fol. 234). Efrain Castro Morales: "Los maestros mayores de la Catedral de México", p. 142. Palacio Nacional, México, Secretaría de Obras Públicas, Unidad Editorial, 1976, p. 300. Efraín Castro Morales, "Juan Montero, ensamblador y arquitecto novohispano del siglo xvis", p. 26. 
do. Juan Montero inició la construcción del tercer cuerpo de la portada del Perdón y posiblemente concluyó el primer cuerpo de las portadas procesionales. Cristóbal de Medina vendría siendo el autor de las portadas del crucero de las modificaciones de la del Perdón y del segundo cuerpo de las portadas procesionales; planeaba concluir el tercer cuerpo de la portada del Perdón y proyectó el tercer cuerpo de las portadas procesionales.

Sin embargo, me gustaria profundizar un poco más en el problema de la paternidad de las columnas salomónicas de las portadas catedralicias con el objeto de reforzar la cronología que hemos establecido.

Las únicas que se tienen documentadas son las de las portadas del crucero, concluidas en 1688 y 1689 bajo la dirección de Cristóbal de Medina. Ahora bien, entre las obras salomónicas de la ciudad de México existen dos que se pueden considerar más o menos contemporáneas a estas portadas: los templos de Santa Teresa la Antigua y San Agustín. El primero fue proyectado y dirigido por Gristóbal de Medina ${ }^{24}$ y el segundo también se le puede atribuir. ${ }^{25}$ Con esto tenemos un común denominador entre todas estas obras: el autor.

Pero ¿qué relación formal podemos encontrar entre los tres grupos de columnas salomónicas? Realmente lo primero que notamos son diferencias: las de catedral y el primer cuerpo de Santa Teresa tienen un helicoide muy cerrado, mientras que las de San Agustín lo tienen más abierto; las de Santa Teresa son tritóstilas, en tanto que las de catedral y San Agustín no; las de Santa Teresa y la catedral prácticamente no modifican la estabilidad del fuste, en tanto que las de San Agustín tienen más movimiento; sin embargo todas tienen dos elementos comunes: los senos, es decir, la sección convexa de los fustes salomónicos, son acha-

24 AN (Notario Fernando Veedor: 18 de enero de 1679 , fol 26 vto-27 vto.) y AC (Arquitectura: 6). Dato proporcionado por Elisa Vargas Lugo, paleogxafía de Guillermina Ramirez. Martha Fernández, Arquitectura y gobierno virreinal, Apud: AN (Notario José de Anaya, año de 1678, fol. 209). Dato del I. I. E. y AGI (Audiencia de México: 163 , ramo 2 , doc. 28).

25 Martha Fernández, Arquitectura y gobierno virreinal; Apud: AGI (Audiencia de México: 163, ramo 2, doc. 28).

Abreviaturas de los archivos documentales citados

AC: Archivo Cervantes México, D. F.

AGI: Archivo General de Indias. Sevilla, España.

AGN: Axchivo General de la Nación. México, D. F

AN: Archivo General de Notarías. México, D. F.

ASM: Archivo del Sagrario Metropolitano. México, D. F. 
flanados, esto es, no redondeados sino angulosos, y las gargantantas (la sección cóncava de los fustes salomónicos) están recorridas por una guía formada por motivos ornamentales. El gusto por esta última es tan evidente en las tres obras que a los apoyos del segundo cuerpo de las portadas del templo de Santa Teresa los dota de impresión salomónica sin tener fustes salomónicos, esto es, que lo único que adquiere movimiento en esos fustes es ese motivo decorativo.

Ahora volvamos a las portadas catedralicias. De acuerdo a la cronología que hemos establecido para el segundo cuerpo de las portadas procesionales, resultan asimismo atribuibles a Cristóbal de Medina; no obstante, parece pertinente ahora tratar de relacionarlas estilísticamente con las obras documentadas del arquitecto. Las columnas salomónicas de estas portadas tienen gargantas pronunciadas y su helicoide arranca desde las basas, lo que las identifica con las columnas salomónicas del templo de San Agustín, pero además poseen también los senos achaflanados y la guía de motivos ornamentales a lo largo de sus gargantas, como las portadas del crucero, las de Santa Teresa la Antigua y la citada de San Agustín.

A xaíz de estos instrumentos de análisis, creo que no resulta demasiado aventurado concluir que cronológica y estilísticamente el autor de las columnas salomónicas de las portadas de la catedral de México debió ser Cristóbal de Medina.

\section{Las principales hipótesis}

En vista del carácter reflexivo de este artículo parece conveniente tratar de fijar las hipótesis principales que he planteado a lo largo del estudio.

Primero: a partir de las noticias proporcionadas por Diego Angulo se deduce que los arquitectos contemplaron en 1699 el proyecto de un tercer cuerpo en las portadas procesionales. Si a esto añadimos que el proyecta de la portada del Perdón incluía ese mismo número de cuerpos, hemos de suponer que las tres portadas del imafronte estuvieron proyectadas en tres cuerpos.

Segundo: de la Información Testimonial de Juan Montero, tal como fue publicada por Efraín Castro, se infiere que este arquitecto comenzó a levantar el tercer cuerpo de la portada del Perdón siguiendo el proyecto de Luis Gómez de Trasmonte y Rodrigo Díaz de Aguilera.

Tercero: del análisis de la información anterior propongo el siguiente 
esquema cronológico para la construcción de las portadas catedralicias estudiadas:

\section{Portada del Perdón}

Primer cuerpo: concluido en 1672.

Segundo cuerpo: construido de 1672 a 1678 . Modificado entre 1684 y 1689.

Tercer cuerpo: comenzado entre 1682 y 1684. En 1699 estaba inconcluso.

\section{Portadas procesionales}

Primer cuerpo: construido entre 1682-1683 y 1684 .

Segundo cuerpo: construido entre 1684 y 1689.

Tercer cuerpo: proyectado en 1699.

Portadas del crucero

Oriente: concluida en 1688.

Poniente: concluida en 1689.

Cuarto: conforme a este esquema cronológico y la fecha en que Cristóbal de Medina se hizo responsable de las obras de la catedral de México, le son atribuibles las modificaciones del segundo cuerpo de la portada del Perdón.

Quinto: al tomar en consideración la cronología antes propuesta y las relaciones estilísticas entre los templos de San Agustín y Santa Teresa la Antigua y las portadas del crucero de la catedral de México, podemos atribuir a Cristóbal de Medina el segundo cuerpo de las portadas procesionales y, por lo tanto, la paternidad de todas las columnas salomónicas de las portadas catedralicias.

Después de lo que se ha expuesto, lo único que podemos afirmar es que, pese a todos los esfuerzos no todo está dicho respecto a nuestra catedral. Falta mucho por investigar y es por ello que creo que los lectores habrán de comprender que el sentido de publicar estas reflexiones es ayudar, en la medida de lo posible, la búsqueda e interpretación de nuevos datos en torno a la historia de la catedral de México. 